\title{
A mandiocultura e a produção de farinha: um estudo sobre a farinha produzida em Vitória de Santo Antão-PE
}

\section{Leonardo Rodrigues Ferreira}

Universidade Federal Rural de Pernambuco. Unidade Acadêmica de Serra Talhada. Av. Gregório Ferraz Nogueira, S/N . Bairo José Tomé de Souza Ramos. Serra Talhada-PE (CEP 56909-535). E-mail: Irferreira.adm@gmail.com.

Resumo. A mandioca é um dos principais alimentos para milhares de pessoas que vivem nos países em desenvolvimento. Este trabalho tem objetivo apresentar a produção de mandioca e a fabricação de farinha em Vitória de Santo Antão na Zona da Mata Pernambucana. A pesquisa foi realizada com os produtores rurais de mandioca e a fabricação de farinha no Assentamento Açude Grande, zona rural do Município de Vitória de Santo Antão, em Pernambuco. Em um universo de 24 famílias, foi analisada uma amostra aleatória de 15 produtores, participantes do Projeto Corredor da Farinha. Os resultados da pesquisa revelaram a baixa escolaridade dos agricultores, a ausência da utilização de tecnologias adequadas devido aos recursos limitados, a resistência a mudanças e a falta de estrutura humana e financeira para os treinamentos e as capacitações desses produtores. Durante a pesquisa constatamos que a participação da produção da farinha de mandioca e seus derivados são de grande importância na economia local. Verificamos a importância de se preservar o cultivo da mandioca na região, pois a produção da cultura, ainda é realizada de forma rudimentar, como a produção de farinha que é feita de maneira artesanal, com tradições culturais.

Palavras-chave: Farinha, Pernambuco, Mandioca, Economia.

Abstract. The cultivation of cassava and production of flour: a study of the flour produced in Vitória de Santo Antão Municipality, Pernambuco. Cassava is one of the main food for thousands of people living in developing countries. This study aimed to present the production of cassava and production of flour in Vitória de Santo Antão in the Area of the Pernambuco Forest. The survey was conducted with farmers of cassava and flour production in the Settlement Açude Grande, rural zone of the Vitória de Santo Antão Municipality, Pernambuco. In a universe of 24 families, a random sample of 15 producers, participants Flour Corridor Project was analyzed. The survey results revealed the low education level of farmers, the lack of use of appropriate technologies due to limited resources, resistance to change and lack of human and financial framework for the training and the skills of these producers. During the research we found that the participation of cassava flour production and its derivatives are of great importance in the local economy. We realize the importance of preserving the cultivation of
Recebido: 20/11/2015

Aceito: 14/12/2015

Publicado: 31/12/2015

Acesso Aberto Artigo completo

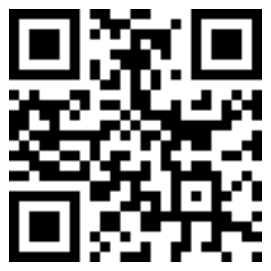


cassava in the region, because the crop production is still done in a rudimentary way, like the production of flour that is made in a traditional manner, with cultural traditions.

Keywords: Flour, Pernambuco, Cassava, Economy.

\section{Introdução}

A produção de mandioca em Pernambuco é basicamente direcionada ao consumo humano, na forma de farináceos, sendo insignificante a produção de fécula de mandioca para uso da indústria no estado. Apesar de a produção ser centralizada em pequenas propriedades, 0 baixo uso de tecnologia, permite uma lavoura de subsistência, porém, pelo potencial da cultura, essas áreas podem ser melhor aproveitadas, para obter maior produtividade da lavoura (Barros, 2005).

A mandioca em Pernambuco é cultivada pelo pequeno produtor rural da agricultura familiar, e é uma agricultura de subsistência, cujas sobras são comercializadas, principalmente para o sustento da família do pequeno produtor.

Segundo Gaspar (2014), a matéria prima para se fabricar a farinha de mandioca, é uma planta da Família Eufrobiacea, um tubérculo, conhecido popularmente na região como macaxeira ou mandioca, sempre cultivada é utilizado na alimentação da população pernambucana.

Em Pernambuco existiam várias tipos de mandioca, como: branquinha, cruvela, caravela ou mamão, engana-ladrão, fria ou da mata, landim, manipeba, vermelha, entre outras, além da mandioca brava, muito venenosa (Gaspar, 2014).

O objetivo geral deste trabalho é apresentar a produção de mandioca e a fabricação de farinha em Vitória de Santo Antão/PE. Para isso temos os seguintes objetivos específicos: Identificar o perfil do trabalhador rural, produtor de mandioca em Pernambuco; Analisar os indicadores de produção na propriedade rural de mandioca e verificar o processo da fabricação de farinha em Vitória de Santo Antão-PE.

A metodologia utilizada na realização desse trabalho de pesquisa se originou no município de Vitória de Santo Antão em Pernambuco, escolhido para a amostra da região, como foram utilizados os instrumentos da pesquisa, livros temáticos, artigos científicos, dissertações e teses sobre o tema, questionários e observação sistemática, a definição do tipo da pesquisa foi baseada na técnica qualitativa descritiva, como a análise da forma utilizada no tratamento dos dados coletados para realização e conclusão da pesquisa.

\section{Material e métodos}

A pesquisa de campo foi realizada no assentamento Açude Grande, na Zona Rural do Município de Vitória de Santo Antão, em Pernambuco, com produtores da agricultura familiar que trabalham no plantio da mandioca e fabricação de farinha, que foram beneficiados através do projeto de assistência técnica, Corredor da Farinha, executado pela Sociedade Nordestina de Ecologia (SNE), financiado pelo Programa de Apoio ao Desenvolvimento Sustentável da Zona da Mata de Pernambuco (PROMATA). A escolha do Município de Vitória de Santo Antão para a aplicação da pesquisa justifica-se por ser o mais representativo entre os outros municípios participantes do projeto, por sua central de abastecimento, por possuir vários supermercados e feiras livres, se destacando entre os outros municípios do projeto. A cultura da mandioca representa perfeitamente a agricultura familiar na Região da Mata do estado, pelo fato de o Município de Vitória ser o maior distribuidor da cultura de mandioca para o consumidor final; esse município, entre outros aspectos, representa a cidade polo para os municípios vizinhos. Dessa forma, espera-se a existência de um padrão dos indivíduos participantes da pesquisa, por sua realidade econômica e social.

Nesta pesquisa, entende-se por agricultor familiar aquele que realiza junto 
com sua família as atividades do campo, cuja renda predominante é do trabalho em sua propriedade, e cuja administração do estabelecimento é de responsabilidade da própria família.

O Assentamento Açude Grande, está localizado na Zona da Mata Pernambucana, mais especificamente no Município de Vitória de Santo Antão. Segundo o Instituto Nacional de Colonização e Reforma Agrária (INCRA), o imóvel rural denominado Engenho Açude Grande, situado na zona rural do município, é cadastrado no órgão sob $0 \quad \mathrm{n}^{0}$ 232.203.011.576-1, estabelecendo desapropriações por interesse social, para fins de reforma agrária. A distribuição das terras no imóvel foi feita no ano civil de 1996, conforme Instrução Normativa INCRA n ${ }^{\circ}$ 08/1993.

O imóvel possui área registrada de 300 ha, situando-se a 67,2 km do Recife, com acesso através da Rodovia BR-232, até o entroncamento da Rodovia PE-50, e mais $10,5 \mathrm{~km}$. A vegetação ainda apresenta resquícios de mata atlântica, as espécies mais comuns são pau-ferro, imbaúba e sucupira branca (INCRA, 2009).

Quanto à educação, as escolas mais próximas ficam no Engenho Serra, assentamento do INCRA, (a $1 \mathrm{~km}$ da sede), e no Sítio Cacimba, a $2 \mathrm{~km}$ da sede (imóvel), nas escolas ensina-se apenas até o ensino fundamental; o complemento dos estudos, Ensino Médio, apenas no Município de Vitória de Santo Antão.

Durante a vistoria do INCRA, em março de 1997, o imóvel achava-se invadido por 41 famílias de trabalhadores sem-terra (INCRA, 2009).

A estrada que dá acesso à localidade é de barro, estreita e mal conservada, principalmente nos dias de chuva. $\mathrm{O}$ transporte urbano não chega até esta localidade. Os meios de locomoção de acesso são a carro e a moto, e quem não dispõe de tais veículos de locomoção, percorre o trecho a pé ou carro de boi.

\section{buco}

\section{A mandiocultura em Pernam-}

A utilização da mandioca em Pernambuco é basicamente para consumo humano; essencialmente seu principal derivado é a farinha de mandioca, que é julgada um bem inferior. Se essa teoria é verdade, e os resultados presumem que seja, os programas de crescimento e renda fundamentados no desenvolvimento da lavoura de mandioca devem necessariamente apresentar alternativas econômicas para os produtores utilizarem os excedentes financeiros obtidos com o programa, sob o risco de gerar um excesso de oferta de produto com enfraquecimento dos preços e perda dos resultados obtidos (Barros, 2005).

Segundo Barros (2005), para estimar a produção de mandioca serão utilizados como referência básica os valores apresentados pelo Instituto Brasileiro de Geografia e Estatística (IBGE), através da Pesquisa Agrícola Municipal (PAM) para os anos de 1990 a 2003. A Tabela 1, que segue, demonstra em detalhes esses valores, mencionando a produtividade do Brasil, da região Nordeste, essencialmente do estado de Pernambuco e de suas mesorregiões.

$\mathrm{Na}$ Tabela 1, é apresentada a evolução histórica da produção de mandioca, no Brasil, na região Nordeste e especificamente em Pernambuco e em suas regiões nos anos de 1990 até 2003; essa trajetória identifica a importância da cultura para a agricultura familiar e marca períodos em que, por vários motivos, a produção variou em relação aos anos e como essa cultura é importante para a região nordeste, principalmente para o estado de Pernambuco, destacando a região da mata pernambucana. Como pode ser deduzido pela apresentação dos dados na referida tabela, a participação do Nordeste na produção nacional caiu de 49\% em 1990 para 36\% em 2003, em Pernambuco; a participação na produção do Nordeste também caiu de $10 \%$ para $6 \%$ no mesmo período, enquanto a Zona da Mata pernambucana também perdeu algum espaço na produção, de $20 \%$ para $16 \%$, entre 1990 e 2003.

Conforme a Tabela 2, que apresenta a produção de mandioca em Pernambuco, distribuída nas mesorregiões, microrregiões em alguns municípios do estado e sua participação na produção de mandioca, o que se verifica é a grande participação do 
Tabela 1. Quantidade produzida (t) de mandioca, no Brasil, na Região Nordeste e no Estado de Pernambuco.

\begin{tabular}{c|c|c|c|c|c|c|c|c}
\hline Ano & Brasil & Nordeste & Pernambuco & $\begin{array}{c}\text { Sertão } \\
\text { Pernambuco }\end{array}$ & $\begin{array}{c}\text { São Francisco } \\
\text { Pernambucano }\end{array}$ & $\begin{array}{c}\text { Agreste } \\
\text { Pernambucano }\end{array}$ & $\begin{array}{c}\text { Mata } \\
\text { Pernambucana }\end{array}$ & $\begin{array}{c}\text { Metropolitana } \\
\text { de Recife }\end{array}$ \\
\hline 1990 & 24.322 .133 & 11.832 .690 & 1.131 .122 & 216.414 & 26.447 & 628.756 & 221.363 \\
\hline 1991 & 24.537 .505 & 12.001 .254 & 1.126 .161 & 174.792 & 24.265 & 667.985 & 217.281 & 38.142 \\
\hline 1992 & 21.918 .600 & 10.059 .895 & 1.016 .821 & 158.542 & 30.096 & 576.880 & 212.691 & 31.838 \\
\hline 1993 & 21.855 .690 & 8.107 .441 & 769.167 & 101.015 & 26.141 & 423.532 & 171.657 & 46.612 \\
\hline 1994 & 24.464 .293 & 9.223 .187 & 729.350 & 55.660 & 22.926 & 466.445 & 136.081 & 48.238 \\
\hline 1995 & 25.422 .959 & 10.946 .619 & 874.769 & 128.005 & 35.035 & 523.625 & 146.192 & 41.912 \\
\hline 1996 & 17.743 .155 & 6.318 .030 & 671.509 & 116.084 & 22.580 & 386.875 & 110.528 & 35.442 \\
\hline 1997 & 19.896 .205 & 6.819 .928 & 716.671 & 103.176 & 46.030 & 402.635 & 121.027 & 43.803 \\
\hline 1998 & 19.502 .717 & 6.340 .459 & 419.327 & 97.280 & 29.315 & 175.792 & 73.137 & 43.803 \\
\hline 1999 & 20.864 .340 & 6.353 .759 & 353.431 & 102.085 & 6.882 & 128.242 & 60.107 & 56.115 \\
\hline 2000 & 23.040 .670 & 8.008 .053 & 377.757 & 103.315 & 8.960 & 200.203 & 45.924 & 19.355 \\
\hline 2001 & 22.580 .282 & 7.544 .387 & 410.849 & 105.572 & 8.983 & 205.596 & 81.768 & 8.930 \\
\hline 2002 & 23.148 .303 & 8.266 .588 & 483.634 & 127.995 & 8.758 & 239.995 & 92.366 & 14.520 \\
\hline 2003 & 21.964 .082 & 7.963 .262 & 440.447 & 119.485 & 8.560 & 223.148 & 69.864 & 19.390 \\
\hline
\end{tabular}

Fonte: IBGE. Produção Agrícola Municipal (vários anos).

Tabela 2. Área plantada, produção da lavoura temporária.

\begin{tabular}{|c|c|}
\hline $\begin{array}{l}\text { No Brasil, na Região Nordeste, em Pernambuco e suas mesorregiões geográfica, microrregião } \\
\text { geográfica e nos seus municípios produtores de mandioca. }\end{array}$ & Área (ha) \\
\hline Brasil & 1.941 .104 \\
\hline Nordeste & 945.329 \\
\hline Pernambuco & 58.611 \\
\hline Sertão Pernambucano & 19.257 \\
\hline São Francisco Pernambucano & 1.175 \\
\hline Agreste Pernambucano & 27.789 \\
\hline Mata Pernambucana & 5.688 \\
\hline Metropolitana de Recife & 4.702 \\
\hline Araripina & 16.100 \\
\hline Salgueiro & 1.085 \\
\hline Pajeú & 1.052 \\
\hline Sertão do Moxotó & 1.020 \\
\hline Petrolina & 835 \\
\hline Itaparica & 340 \\
\hline Vale do Ipanema & 4.880 \\
\hline Vale do Ipojuca & 5.895 \\
\hline Alto Capibaribe & 161 \\
\hline Médio Capibaribe & 778 \\
\hline Garanhuns & 14.620 \\
\hline Brejo Pernambucano & 1.455 \\
\hline Mata Setentrional Pernambucana & 855 \\
\hline Vitória de Santo Antão & 760 \\
\hline Mata Meridional Pernambucana & 4.073 \\
\hline Itamaracá & 1.902 \\
\hline Recife & 2.450 \\
\hline Suape & 350 \\
\hline Fernando de Noronha & - \\
\hline Vitória de Santo Antão & 140 \\
\hline
\end{tabular}

Lavoura temporária = Mandioca - Ano = 2007 - Área plantada (Hectares). Fonte: IBGE - Produção Agrícola Municipal. 
Agreste e do Sertão pernambucanos, que juntos possuem mais da metade da produção do estado; outra informação relevante é que as cidades de destaque como Garanhuns e Araripina que representam um polo de distribuição da mandioca. Ressaltamos a produção do município de Vitória de Santo Antão, que é o objeto de estudo da pesquisa, o qual é demonstrado em detalhes, como é sua participação na área de cultivo.

A Tabela 3 mostra que segundo dados do IBGE (2009), na contagem da população para o ano de 2007, os municípios apresentados são todos integrantes do projeto Corredor da Farinha; o que se verifica de forma clara é o destaque do município de Vitória de Santo Antão como o mais importante da região, sua população supera a soma de todos os outros que fazem parte do projeto.
Conforme a Tabela 4, que apresenta dados socioeconômicos, observa-se que nessa região é marcante a evidência da pobreza e a falta de oportunidades, refletindo no aumento da pobreza e na degradação do meio ambiente, e em resultados de poucas atuações em políticas públicas para o desenvolvimento regional. Quanto ao IDH na Zona da Mata, houve uma significativa melhora entre os anos de 1991 e 2000, passando respectivamente de 0,5333 para 0,637 ; no entanto ainda se encontra abaixo do IDH estadual, situado em 0,705. Grande parte da população menos favorecida encontra-se no município de Chã de Alegria, como revelam os dados; apresenta-se também nesse município a menor renda per capita, nesses municípios, outro dado estudado foram os índices de Gini (Pimentel, 2008).

Tabela 3. População residente na área de abrangência do projeto Corredor da Farinha.

\begin{tabular}{ll}
\hline Município (PE) & Habitantes \\
\hline Vitória de Santo Antão & 121.233 \\
Glória do Goitá & 27.397 \\
Chã de Alegria & 11.636 \\
Lagoa do Itaenga & 19.987 \\
Pombos & 21.810 \\
Feira Nova & 19.276 \\
\hline
\end{tabular}

Variável = População residente (Pessoas) Ano = 2007. Fonte: IBGE, 2009.

Tabela 4. Indicadores sócio-econômicos da área de abrangência do projeto Corredor da Farinha.

\begin{tabular}{lccccc}
\hline Município & Analfabetismo & $\begin{array}{c}\text { Renda per capita } \\
\text { (R\$) em 2000 }\end{array}$ & $\begin{array}{c}\text { Proporção } \\
\text { de Pobres } \\
(\%)\end{array}$ & Gini & IDH \\
\hline Pernambuco & 28,3 & 183,80 & 51,3 & 0,67 & 0,705 \\
Feira Nova & 49,6 & 107,00 & 62,2 & 0,57 & 0,641 \\
Glória do Goitá & 50,2 & 84,50 & 70,9 & 0,53 & 0,636 \\
Lagoa de Itaenga & 41,5 & 82,60 & 67,5 & 0,52 & 0,638 \\
Pombos & 45,0 & 98,00 & 65,3 & 0,55 & 0,606 \\
Chã de Alegria & 44,5 & 69,70 & 74,8 & 0,56 & 0,629 \\
Vitória de Santo Antão & 32,3 & 129,30 & 54,4 & 0,57 & 0,663 \\
\hline
\end{tabular}

Fonte: SNE, 2008.

Segundo a PNUD, o Índice de Gini mede o grau de desigualdade existente na distribuição de indivíduos segundo a renda domiciliar per capita. Seu valor varia de 0 , quando não há desigualdade (a renda de todos os indivíduos tem o mesmo valor), a 1, quando a desigualdade é máxima (apenas um indivíduo detém toda a renda da sociedade e a renda de todos os outros indivíduos é nula). 


\section{nambuco}

A produção de farinha em Per-

Conforme Gaspar (2009), os índios que habitavam a região que hoje é Pernambuco, chamavam as suas plantações ou roças, de mandiotuba. A mandioca é também conhecida na região do nordeste como macaxeira, para a sua utilização era condicionada de forma, amolecida, fermentada ou apodrecida para a fabricação da farinha ou extração da goma, de mandiopuba, e a farinha misturada com água, o pirão, de uypeba.

A casa de farinha é o local onde se transforma a mandioca em farinha, ingrediente usado na fabricação de vários gêneros alimentícios, entre os quais temos 0 beiju, conhecido pelos índios como mbyú, muito apreciado na região Nordeste do Brasil.

Segundo Gaspar (2009), em 1551, o padre jesuíta Manoel da Nóbrega quando veio de visita a Pernambuco, escreveu sobre o beiju e as farinhas fabricadas pelos indígenas.

No período do Brasil Colonial, a farinha de mandioca era muito utilizada para a alimentação dos escravos, dos criados das fazendas e engenhos, além de servir também como mantimento nas viagens dos portugueses.

A produção de farinha de mandioca inicia com o plantio das manivas, que é um arbusto da planta da mandioca. Após a colheita da raiz (tubérculo), a mandioca é levada direto da roça para a casa de farinha, onde é descascada e colocada na água para amolecer e fermentar ou pubar. $\mathrm{Na}$ sequência, é triturada ou ralada em pilão ou no ralador ou caititu. A mandioca ralada vai caindo em um cocho, sendo depois prensada no tipiti $($ tipi $=$ espremer e ti $=$ líquido, na língua Tupi) para retirada do líquido venenoso chamado manipueira (ácido anídrico). Depois de peneirada e torrada, a farinha está pronta para o consumo (Gaspar, 2009).

Na visão de Guibu (2014), após a moagem, a massa é prensada por duas toras unidas por parafusos feitos em troncos. $\mathrm{O}$ processo separa o produto da manipueira, líquido que possui o veneno da mandioca. A pasta passa pela urupema, peneira feita com cipó, e segue depois para um forno redondo parecido com uma grande frigideira, de tijolos de barro. Fica lá por duas horas, mexida com um rodo de pau.

Para fabricar a farinha, os agricultores usam a mandioca brava, mais venenosa. A macaxeira (mandioca mansa ou doce) é usada para outros pratos.

De acordo com Guibu (2014), alimento típico da cozinha Pernambucana, a farinha é ingrediente indispensável na mesa da população na Zona da Mata, em Pernambuco, a farinha ainda é fabricada em velhas instalações, erguida próxima a canaviais. Nas pequenas e rusticas fábricas antigas, pequenos produtores realizam todo o processo industrial de forma artesanal. $\mathrm{O}$ equipamento é formado de madeira e barro. O trabalho é realizado por pessoas da comunidade, e alguns são contratados como diaristas, no processo da fabricação de farinha.

Segundo Gaspar (2009), o líquido que resta da pubagem tem um grande teor alcoólico. No Estado do Pará, esse líquido, depois de ser submetido à ação do sol ou do fogo para retirar sua toxidade, é utilizado no preparo do tucupi, uma espécie de molho muito estimado na cozinha amazônica com o famoso pato no tucupi.

Conforme Guibu (2014), em algumas áreas, a massa da mandioca, que sobra durante o processo, é utilizada como goma para engomar roupa ou para fabricar alimentos como mingau, papa, sequilho, bolo, tapioca.

Nas casas de farinha situadas em Pernambuco, mas especificamente em Vitória de Santo Antão, área pesquisada, as atribuições são separadas: os homens são responsáveis pela atividade de arrancar a mandioca do campo e leva-la para a casa de farinha. As mulheres e crianças raspam os tubérculos e extraem o amido ou polvilho. Normalmente o trabalho vai pela noite, quando ocorrem as chamadas farinhadas. A casa de farinha contribuiu para segurar o homem à terra, transformando a mandioca um relevante alimento, responsável pela redução da fome em algumas regiões brasileiras (Guibu, 2014).

Para Freitas (2014), na maioria dos casos, o alimento é fabricado de maneira 
artesanal nas casas de farinha, como são chamadas as áreas de fabricação de farinha, utilizadas por pequenos produtores da agricultura familiar, para o processamento da raiz. Segundo o mesmo autor, nessas pequenas e rusticas fábricas a comunidade se mobiliza nos chamados "desmanchas", quando a mandioca é transformada em farinha. Todo esse procedimento é normalmente feito de forma manual, iniciando com a colheita, raspagem, prensagem, peneira e forno.

A Tabela 5 menciona o valor e a produção da farinha, principal produto da mandioca, e faz comparações com outros produtos, que são a goma e a tapioca; nesse aspecto, verifica-se o destaque de outros estados da Região Nordeste em relação a Pernambuco, como o Maranhão e a Bahia, que possuem números superiores aos outros estados do nordeste. A produção de Pernambuco é ainda inferior a estados como Ceará e Sergipe.

Esses resultados mostram que houve, ainda que em pequena escala, reorganização da área produtiva tanto em nível nacional quanto regional, melhorando as propriedades agrícolas que cultivam a mandioca, essencialmente as dos agricultores familiares da produção de subsistência, porque é com instrumentos simples como a utilização da informação que se alcança maior produtividade.

Nesta região temos duas tipologias básicas de casas de farinha. No município de Vitória de Santo Antão-PE, temos envolvimento direto com a agricultura familiar, onde pessoas da mesma família na agricultura local, a produção ocorre com baixa capacidade produtiva, porém, o produto é de boa qualidade e são consumidos em parte pelos próprios produtores, a outra parte o excedente é vendido em feiras livres locais, ou para atravessadores que comercializam $\mathrm{o}$ produto em larga escala. E importante salientar que algumas pequenas propriedades, muitas vezes não produzem a matéria prima, ou seja, a mandioca, mas por possuírem a casa de farinha, compram a mandioca bruta, e fabricam a farinha para sua subsistência.
Temos outra tipologia, na qual Freitas (2014) relata que são as fabricas de farinhas automatizadas, encontramos algumas na região, com larga produção é utilizada para a produção de farinha para a comercialização.

O Censo Agropecuário do IBGE (1996) considerou como estabelecimento agropecuário todo terreno de área contínua, independente do tamanho ou da situação (urbana ou rural), formado de uma ou mais parcelas, subordinado a um único produtor, onde se processe exploração agropecuária, ou seja: o cultivo do solo com culturas permanentes e temporárias, inclusive hortaliças e flores; a criação, recriação ou engorda de animais de grande e médio porte; a criação de pequenos animais; a silvicultura ou o reflorestamento; e a extração de produtos vegetais.

Conforme a Tabela 6, que trata dos produtores rurais que possuem casas de farinha, nos municípios atendidos pelo projeto da SNE, o que possui maior representatividade é Glória do Goitá, com o maior número de produtores participantes do projeto e o que possui o maior número de casas de farinha; segundo Vital e Pimentel (2008), os produtores informaram que necessitam de qualquer melhoria em sua propriedade e que continuam usando os fornos manuais no processo de fabricação da farinha. A estrutura das propriedades se revela a mais inconstante possível; a mais habitual encontrada é a de alvenaria com piso em cimento, entretanto algumas outras estruturas também são encontradas, como as construções em alvenaria com piso de terra.

Diante das evidências da Tabela 6, verifica-se que a informação direcionada ao controle gerencial na área rural não é utilizada; a tecnologia, que trata do estudo da técnica, não está apenas relacionada com as ferramentas mecanizadas, mas também com a forma como se faz algo; nesse caso, a informação aprimora a maneira de se fazer alguma coisa.

Na Região da Mata do Estado de Pernambuco, especificamente no Município 
Tabela 5. Produção e valor da produção de farinha de mandioca e tapioca e/ou goma, segundo a Região Nordeste e seus estados no ano de 2006.

\begin{tabular}{|c|c|c|c|c|c|c|c|c|c|c|}
\hline \multirow{4}{*}{$\begin{array}{l}\text { Grandes Regiōes e } \\
\text { Unidades da Federação }\end{array}$} & \multicolumn{10}{|c|}{ Produção e valor da produção } \\
\hline & \multicolumn{5}{|c|}{ Farinha de mandioca } & \multicolumn{5}{|c|}{ Tapioca e/ou goma } \\
\hline & \multirow{2}{*}{$\begin{array}{l}\text { Estabele- } \\
\text { cimentos }\end{array}$} & \multicolumn{2}{|c|}{$\begin{array}{c}\text { Produção com matéria- } \\
\text { prima }\end{array}$} & \multirow{2}{*}{$\begin{array}{l}\text { Quantidade } \\
\text { vendida ( } t \text { ) }\end{array}$} & \multirow{2}{*}{$\begin{array}{c}\text { Valor da } \\
\text { produção } \\
(1.000 \text { RS) }\end{array}$} & \multirow{2}{*}{$\begin{array}{l}\text { Estabele- } \\
\text { cimentos }\end{array}$} & \multicolumn{2}{|c|}{$\begin{array}{c}\text { Produção com matéria- } \\
\text { prima }\end{array}$} & \multirow{2}{*}{$\begin{array}{l}\text { Quantidade } \\
\text { vendida ( } t \text { ) }\end{array}$} & \multirow{2}{*}{$\begin{array}{l}\text { Valor da } \\
\text { produção } \\
\text { (1.000 RS) }\end{array}$} \\
\hline & & Própria (t) & $\begin{array}{l}\text { Adquirida } \\
\text { (t) }\end{array}$ & & & & Própria (t) & Adquirida (t) & & \\
\hline Brasil & 264.882 & 1.193 .214 & 139.660 & 948.190 & 941.981 & 40.251 & 40.991 & 5.911 & 30.736 & 48.638 \\
\hline Nordeste & 177.655 & 591.896 & 79.823 & 407.057 & 418.828 & 31.102 & 33.232 & 3.412 & 22.062 & 37.190 \\
\hline Maranhão & 47,030 & 234.445 & 20.385 & 133.678 & 196.426 & 3.316 & 3.783 & 466 & 3.362 & 4.395 \\
\hline Piaui & 14.345 & 17.881 & 1.117 & 9.803 & 8.579 & 11.115 & 8.937 & 458 & 4.932 & 11.042 \\
\hline Ceará & 16.747 & 31.324 & 2.771 & 17.225 & 16.651 & 7.452 & 5.576 & 280 & 2.173 & 5.696 \\
\hline Rio Grande do Norte & 516 & 2.829 & 3.625 & 5.689 & 1.994 & 121 & 127 & 114 & 215 & 145 \\
\hline Paraiba & 3.078 & 3.967 & 1.529 & 3.166 & 2.525 & 156 & 15 & 72 & 78 & 18 \\
\hline Pernambuco & 6.775 & 17.351 & 5.721 & 15.953 & 9.974 & 311 & 256 & 88 & 322 & 321 \\
\hline Alagoas & 5.978 & 23.832 & 2.892 & 12.289 & 16.308 & 128 & 16 & 1 & 14 & 17 \\
\hline Sergipe & 6.176 & 26.033 & 7.663 & 27.499 & 19.492 & 39 & 129 & 73 & 201 & 97 \\
\hline Bahia & 77.010 & 234.234 & 34.121 & 181.754 & 146880 & 8.464 & 14.394 & 1.861 & 10.765 & 15.459 \\
\hline
\end{tabular}

Fonte: IBGE, Censo Agropecuário 2006.

Tabela 6. Disponibilidade de casas de farinha para os agricultores, beneficiados pelo projeto Corredor da Farinha.

\begin{tabular}{lcccr}
\hline Município & $\begin{array}{c}\text { Agricultores } \\
\text { participantes do processo }\end{array}$ & $\mathbf{\%}$ & $\begin{array}{c}\text { Agricultores com Casa de } \\
\text { Farinha }\end{array}$ & $\%$ \\
\hline Vitória de Santo Antão & 23 & 14,38 & 6 & 16,21 \\
Glória do Goitá & 109 & 68,13 & 25 & 67,57 \\
Lagoa de Itaenga & 14 & 8,75 & 6 & 16,21 \\
Pombos & 14 & 8,75 & 0 & 0,00 \\
\hline Total & 160 & 100,00 & 37 & 100,00 \\
\hline
\end{tabular}

Fonte: SNE/SERTA, 2008.

de Vitória de Santo Antão, em sua zona rural, a agricultura predominante ainda é a cana-de-açúcar, seguida da mandioca e da banana, que nos últimos anos tiveram grande participação econômica no município. Conforme o Censo Agropecuário de 2006, a área rural cultivada no município de Vitória de Santo Antão não se forma em sua totalidade pela produção de cana-de-açúcar, lavoura predominante na região da Mata do Estado de Pernambuco, mas também por possuir culturas anuais e permanentes. A exploração da cana-de-açúcar ocupava até pouco tempo $86,45 \%$ do total da área cultivada; as áreas exploradas com outras lavouras, permanentes e temporárias, correspondiam a $13,55 \%$ do total cultivado (CONDEPE/FIDEM, 2006).

\section{O Projeto Corredor da Farinha e a participação de Vitória de Santo Antão-PE}

O projeto Corredor da Farinha tem como objetivo geral: Revitalizar a cadeia produtiva de mandioca na região das bacias hidrográficas do rio Tapacurá e do rio Goitá, envolvendo 120 agricultores e seis casas de farinha de produtores familiares em seis municípios, ofertando serviços de assistência técnica-gerencial e capacitação continuada, visando à qualificação da unidade produtiva familiar frente às dificuldades encontradas no setor da mandiocultura regional (Pimentel, 2008).

O projeto possui como área de abrangência $\quad o$ correspondente a seis municípios distribuídos entre a Zona da Mata e o Agreste Pernambucano: Pombos, 
Vitória de Santo Antão, Glória do Goitá, Lagoa de Itaenga, Chã de Alegria e Feira Nova, situados em duas bacias hidrográficas, a do Rio Tapacurá e a do Rio Goitá, que possuem de grande importância para o abastecimento de água para a região, principalmente, abastecendo a Região Metropolitana do Recife.

A região de abrangência do projeto está situada próxima à Capital Pernambucana, Recife, que possui como principais vias de acesso a Rodovia BR-232 e a Rodovia PE-50, sendo que a via de ligação com o restante do estado, nessa região, é marcante pela grande presença humana no meio rural (cerca de 23\%), possuindo uma população estimada em 226 mil pessoas (Pimentel, 2008).

A mandioca é uma cultura que representa perfeitamente a agricultura familiar por várias razões: segundo a SNE (2009), a mandioca é plantada em sistemas de cultivos consorciados, com o propósito de utilização da área e diversificação de culturas. A mandioca, entre outras culturas, é de produção simples, ideal para o consumo familiar, necessitando de pouca mão de obra, com produção em solos pobres e prejudicados, sendo um alimento abundante em amido, e é a estrutura alimentar das pessoas nas áreas cultivadas; essencialmente nas casas de farinha, o consumo é dos próprios produtores da agricultura familiar.

O projeto Casa de Farinha idealizada pela SNE foi submetido e aprovado pelo PROMATA, que foi o órgão financiador, cabendo à SNE sua execução, que logo que foi iniciada, surgiu outra oportunidade: o edital público da Petrobras Fome Zero 2006. Nesse ano, aconteceu uma oficina para construção, nomeada Corredor da Farinha, cujas diretrizes para uma estratégia de ação foram traçadas, em conjunto, pelos agricultores, donos de casas de farinha, gestores públicos, técnicos e outros interessados (Pimentel, 2008).

A ausência de assistência local para produção de mandioca resultou na vinda de matéria-prima de outros lugares, tais como os estados vizinhos, fazendo com que os donos das casas de farinha fossem obrigados a fazer transferência de recursos financeiros para outros locais, aumentando bastante os custos de produção, diminuindo a competição do setor na região (Pimentel, 2008).

No ano de 2005, iniciaram-se as primeiras conversas com a associação das casas de farinha do Município de Pombos, com o propósito de conscientizá-la da prática do descarte da manipueira nos rios da região, logo foi constatada a decadência da cadeia produtiva da mandioca na região. Entre vários motivos encontrados para o declínio da produção de mandioca, a grande maioria foi devida à doença conhecida por podridão da raiz, agravada principalmente pela ausência de assistência à extensão rural pelo Estado.

A $\quad$ Tabela 7 apresenta os estabelecimentos da agricultura familiar nos municípios da Mata Pernambucana, compreendendo as cidades de Chã de Alegria, Chã Grande, Glória do Goitá, Pombos e Vitória de Santo Antão; essa comparação entre os municípios ratifica a importância de Vitória de Santo Antão para a agricultura familiar dessa região; os números revelam que a cidade se destaca em estabelecimentos, tanto na agricultura familiar quanto na não familiar.

Tabela 7. Estabelecimento e área da agricultura familiar, em Pernambuco e suas Mesorregiões, Microrregiões e Municípios - 2006.

\begin{tabular}{lcccr}
\hline \multirow{2}{*}{$\begin{array}{l}\text { Grandes Regiões e Unidades da } \\
\text { Federação }\end{array}$} & \multicolumn{2}{c}{$\begin{array}{c}\text { Agricultura familiar } \\
\text { Lei no } \mathbf{~ 1 1 . 3 2 6 / 2 0 0 6}\end{array}$} & \multicolumn{2}{c}{ Não familiar } \\
\cline { 2 - 5 } & Estabelecimentos & Área (ha) & Estabelecimentos & Área (ha) \\
\hline Mata Pernambucana & 29.884 & 117.947 & 3.987 & 581.283 \\
Chã de Alegria & 536 & 1.625 & 42 & 407 \\
Chã Grande & 1.290 & 3.420 & 153 & 3.149 \\
Glória do Goitá & 2.450 & 7.573 & 253 & 8.144 \\
Pombos & 1.690 & 4.823 & 82 & 4.955 \\
Vitória de Santo Antão & 2.383 & 7.912 & 377 & 8.863 \\
\hline
\end{tabular}

Fonte: IBGE, Censo Agropecuário 2006. 


\section{Resultados}

Na análise dos dados coletados dos produtores rurais, pelo questionário aplicado, bem como a observação sistemática do trabalho no campo, destes produtores rurais da agricultura familiar, verificou-se que muito dos problemas enfrentados por essa população, deve-se principalmente a falta da escolaridade, que é bastante acentuada, principalmente para os chefes dos domicílios, pois a grande maioria é analfabeta, outros apenas são alfabetizados, problema que reflete, na condução das atividades do campo, pois cada vez mais, se está necessitando de conhecimentos agregados para produção agrícola, e essa população rural, ainda é muito resistente a mudança, foi observado que quanto maior a escolaridade, melhor é a produtividade rural, tendo como critério a capacidade de assimilar os ensinamentos passados pelos técnicos agrícolas.

Os produtores rurais poderiam ter uma condição de vida melhor, se não fosse à ausência dos governos em vários aspectos tais como saúde e educação, no assentamento onde foi realizada a pesquisa não tem posto de saúde, e possui apenas uma escola municipal com ensino até o primeiro grau menor (primeira à quarta série do ensino fundamental), para os filhos dos agricultores, continuarem seus estudos devem se deslocar para a cidade de Vitória, dificultando muito o acesso à educação das crianças dessa região.

A assistência técnica rural para essa comunidade é bastante precária pelos órgãos públicos, a carência de informação em todos os aspectos é enorme, principalmente no que se refere à área agrícola, pois foram identificadas algumas atuações de órgãos no sentido de financiamento agrícola, mas segundo os produtores, a ausência do acompanhamento dos projetos por parte destes órgãos compromete a contrapartida do produtor que é o pagamento do financiamento, que pelo fato do agricultor não conseguir obter a produção pelo projeto, devido as suas precárias condições de trabalho, ficam endividados, tendo que pagar integralmente o financiamento por eles adquiridos.
A utilização das informações técnicas agrícolas, de forma adequada ajuda o pequeno produtor da agricultura familiar, no aumento da produção e em todo o processo da atividade agrícola, como mercado consumidor, ocasionando uma melhor qualidade de vida para o produtor rural.

\section{Conclusão}

O propósito de desenvolver este trabalho de pesquisa foi pautado no interesse de conhecer como se dá o processo de produção da mandioca e a fabricação da farinha na área rural e como os pequenos produtores da agricultura familiar utilizam seus conhecimentos para a produção da farinha. A questão central da pesquisa foi observar o processo de produção e fabricação da farinha da mandioca, as dificuldades desse segmento da agricultura do ponto de vista econômico, que vive num patamar de renda muito baixo.

Os dados e informações, extraídos do censo agropecuário do IBGE (2006) sobre agricultura familiar e a produção de mandioca e a fabricação da farinha da região estudada, demonstraram a capacidade produtiva da cultura da mandioca, onde foi observado in loco o cultivo dessa cultura de subsistência, foram observados vários procedimentos inadequados, como a queimagem e a falta de rotatividade da utilização do solo, que são combatidos pelos técnicos agrícolas da SNE, no sentido de evitar problemas como o empobrecimento do solo e a falta de alternativas em caso de o agricultor possuir uma só colheita, sendo totalmente dependente das oscilações do mercado.

$\mathrm{O}$ perfil dos produtores de mandioca do assentamento Açude Grande na zona rural do município de Vitória de Santo Antão, área da pesquisa, é, em sua maioria, de aposentados com renda mensal de um salário mínimo e média de idade de aproximadamente 58 anos; residem no local há pelos menos 12 anos, e a maioria não concluiu o ensino fundamental.

Os indicadores de produção da mandioca na zona rural do município de 
Vitória de Santo Antão foram o objeto de estudo desta pesquisa, que demonstrou a real situação da cultura, fonte de sobrevivência para muitos agricultores da região estudada; a participação da SNE tem sido decisiva para modificação do cenário da mandioca, nessa região, revitalizando e fortalecendo a cultura, que é tradicional na região nordeste, especificamente do Estado de Pernambuco.

A metodologia de trabalho para o desenvolvimento da assistência técnica rural utilizada pela SNE atende às necessidades dos produtores da agricultura familiar, pois os resultados contribuem significativamente para o início da mudança do cenário produtivo e econômico dessa população beneficiada pelo projeto.

O projeto Corredor da Farinha, desenvolvido e executado pela SNE, desenvolve papel de grande importância para o crescimento e o desenvolvimento da agricultura familiar na região da mata do estado de Pernambuco, contribuindo para o fortalecimento da agricultura, atendendo à agricultura familiar, preenchendo uma lacuna deixada pelos órgãos públicos aos níveis federal, estadual e municipal.

A SNE, não somente fortaleceu a cultura da mandioca nos municípios atendidos pelo projeto, mas também está melhorando a qualidade de vida dessa população, pois sua atuação, não se limita apenas à assistência técnica rural, como também às reais necessidades dos produtores da agricultura familiar, como o incentivo à diversificação de outras culturas, a utilização de tecnologias rurais, orientações para o atendimento ao mercado consumidor, alternativas de rendimentos para o produtor rural, aumento de sua renda familiar, orientações que têm contribuído significativamente para o desenvolvimento desse segmento da agricultura.

Os resultados da pesquisa indicam que a SNE está alcançando seus desafios, promovendo o desenvolvimento da agricultura familiar, contribuindo para a melhoria do meio ambiente. Em contrapartida, é nítida a carência da assistência técnica rural para a agricultura familiar por falta da participação dos governos, que deveriam apoiar, promover e financiar os produtores, mas os órgãos de assistência técnica rural que atuam no estado não conseguem atender à demanda por falta de estrutura humana e financeira que atenda às necessidades dos produtores da agricultura familiar; existe uma grande preocupação desses agricultores com a possibilidade de perder a assistência técnica rural gratuita, promovida pela SNE, pois todos estão cientes de que trata-se de uma ONG, que realiza projetos por tempo determinado, que são renovados periodicamente.

Apesar da relevante participação da SNE na assistência técnica gratuita para os produtores rurais da agricultura familiar, o desenvolvimento das atividades por parte dos técnicos agrícolas é comprometido, muitas vezes, obrigando-os a parar ou reduzir seus trabalhos, por falta de recursos, devido ao termino do projeto, o que é importante salientar é que a SNE possui outros projetos em andamento, como o reflorestágua, que trata do reflorestamento e a conservação das bacias dos rios; os orgânicos, que é outro projeto de incentivo, apoio e preparo dos agricultores para o cultivo de hortas orgânicas que tem todo um padrão de cultivo; são projetos que apoiam o pequeno produtor rural, melhorando a qualidade de vida dessa população.

Concluímos que as políticas públicas utilizadas na geração de emprego e renda devem desenvolver projetos direcionados ao desenvolvimento rural, contribuindo para que os agricultores familiares não saiam para as cidades em busca de melhores condições de vida, porque é do campo que eles tiram sua sobrevivência, contribuindo para o crescimento do meio rural, tornando mais fácil e menos oneroso a administração pública para o governo que queira realizar uma política de desenvolvimento; e, sendo um instrumento indispensável à agricultura familiar, tem uma contribuição importante para o desenvolvimento regional.

Os governantes devem desenvolver políticas que valorizem os pequenos produtores que trabalham na produção familiar de subsistência, proporcionando alternativas tecnológicas e sustentáveis para 
que eles possam desenvolver sua atividade agrícola de forma digna, contribuindo para uma sociedade com menos problemas sociais e com produtos agrícolas, mais acessíveis para a população.

\section{Declaração de conflito de interesses}

Os autores declaram não haver conflitos de interesses.

\section{Referências}

Barros, A. R. Economia de Pernambuco: uma contribuição para o futuro. Recife: Governo do Estado de Pernambuco, 2005. (Relatório).

Brasil. Leis, decretos, etc. Lei ${ }^{0}$ 11.326, de 24 de julho de 2006. Estabelece as diretrizes para a formulação da Política Nacional da Agricultura Familiar e Empreendimentos Familiares Rurais. Disponível em: <http://www.planalto.gov.br/ ccivil_03/_ato2004-2006/2006/lei/111326.htm>. Acesso em: 25 out. 2015.

Casa de Farinha. Da fabricação a revenda. Disponível em: <http://www.tvliberal.com.br/ revistas/npara/edicao8/farinha.htm>. Acesso em: 25 out. 2015.

CONDEPE/FIDEM. Calendário Oficial de Datas Históricas dos Municípios de Pernambuco, 2006. v. 3.

FIAM. Calendário Oficial de Datas Históricas dos Municípios do Interior de Pernambuco. 1994. v. 2. Enciclopédia dos Municípios Brasileiros. IBGE, 1958.
Freitas, E. Modernização da farinha. 2015. Disponível em: $<$ http://diariodonordeste.verdesmares.com.br/ca dernos/regional/casas-de-farinha-passam-porprocesso-de-modernizacao-1.666805>. Acesso em: 22 out. 2015.

Gaibu, F. Cultura da raiz da mandioca, molda e sustenta o país. 2014. Disponível em: $<$ http://www1.folha.uol.com.br/fol/ brasil500/comida3.htm>. Acesso em: 13 jun. 2014.

Gaspar, L. Casa de farinha. Recife: Fundação Joaquim Nabuco, 2014. Disponível em: $<$ http://basilio.fundaj.gov.br/pesquisaescolar/>. Acesso em: 15 set. 2015.

IBGE - Instituto Brasileiro de Geografia e Estatística. Dados Vitória de Santo Antão/PE. Disponível em: <http://biblioteca.ibge.gov.br/ visualizacao/dtbs/pernambuco/vitoriadesantoant ao.pdf>. Acesso em: 25 set. 2015.

INCRA - Instituto Nacional de Colonização e Reforma Agrária. Laudo técnico de vistoria de imóvel rural $n^{\circ}$ 08/93, Engenho Açude Grande. Recife: INCRA, 1997.

SNE - Sociedade Nordestina de Ecologia. Projeto Corredor da Farinha. 2008. Disponível em: <http://dodesign-s.com.br/casasde-farinha/casas-de-farinha.pdf $>$. Acesso em: 15 set. 2015.

Pimentel, A. (Org.). Corredor da Farinha: uma visão de futuro. Recife: SNE, 2008.

Informação da Licença: Este é um artigo Open Access distribuído sob os termos da Licença Creative Commons Attribution, que permite uso irrestrito, distribuição e reprodução em qualquer meio, desde que a obra original seja devidamente citada. 